\title{
Crystalline Manganese Carbonate a Green Catalyst for Biodiesel Production
}

\author{
Yerraguntla Rajeshwer Rao ${ }^{1}$, Pudukulathan Kader Zubaidha², Jakku Narender Reddy ${ }^{1}$, \\ Dasharath Dattatraya Kondhare ${ }^{2}$, Deshmukh Shivagi Sushma ${ }^{2}$ \\ ${ }^{1}$ Department of Chemistry, Govt. City College, Hyderabad, India \\ ${ }^{2}$ School of Chemical Sciences, Swami Ramanand Teerth Marathwada University, Nanded, India \\ Email: yrajeshwer@yahoo.com
}

Received December 19, 2011; revised January 26, 2012; accepted February 7, 2012

\begin{abstract}
Crystalline manganese carbonate was found to be a versatile green, non corrosive and environmental friendly catalyst for transesterification of vegetable oils. Its use as catalyst in the transesterification process involving methanol and vegetable oils (palm, rapeseed, groundnut, coconut and caster oils) resulted in a conversion rate of $80 \%-95 \%$ in the production of biodiesel. The chemical composition of the obtained biodiesel was studied by GC-MS analysis and showed the presence of linoleic, oleic, palmitic, and stearic acids methyl esters to be the major compounds. Manganese carbonate in comparison with other solid catalysts was found to decrease the reaction time and temperature concomitant with an increase of biodiesel yield. Finally, the effect of various parameters including methanol quantity, catalyst amount, reaction time and temperatures on the production of biodiesel was investigated.
\end{abstract}

Keywords: Biodiesel; Vegetable Oils; Manganese Carbonate; Green Catalyst; Transesterification

\section{Introduction}

Rising petroleum prices and continuous increase of petroleum usage may drive the world, in near future, to feel the pinch of deficiency of transportation fuels. Biodiesel as an alternative fuel for diesel engines is becoming increasingly important due to diminishing petroleum resource $[1,2]$. Various attempts are being made for the search of new catalysts and vegetable oil sources, in transesterification reactions, for the production of biodiesel [35]. Biodiesel synthesis using solid catalysts instead of homogeneous catalysts could potentially lead to cheaper production cost by enablingreuse of the catalyst. Biodiesel is produced by the transesterification of triglycerides of re- fined or edible and non-edible oils by using alcohol and alkaline catalyst. The transesterification process consists of sequences of three consecutive reversible reactions, which includes conversion of triglycerides to diglycerides, followed by diglycerides to monoglycerides. The glycerides are converted in to glycerol and yield one ester molecule in each step [6]. The overall transesterification reaction can be represented by the following Scheme 1. The reaction is normally performed at reflux temperature; the glycerol and FAME (fatty acid methyl ester) are separated by settling after catalyst neutralization. The crude biodiesel and glycerol obtained are then purified. There are different transesterification processes that can be applied to

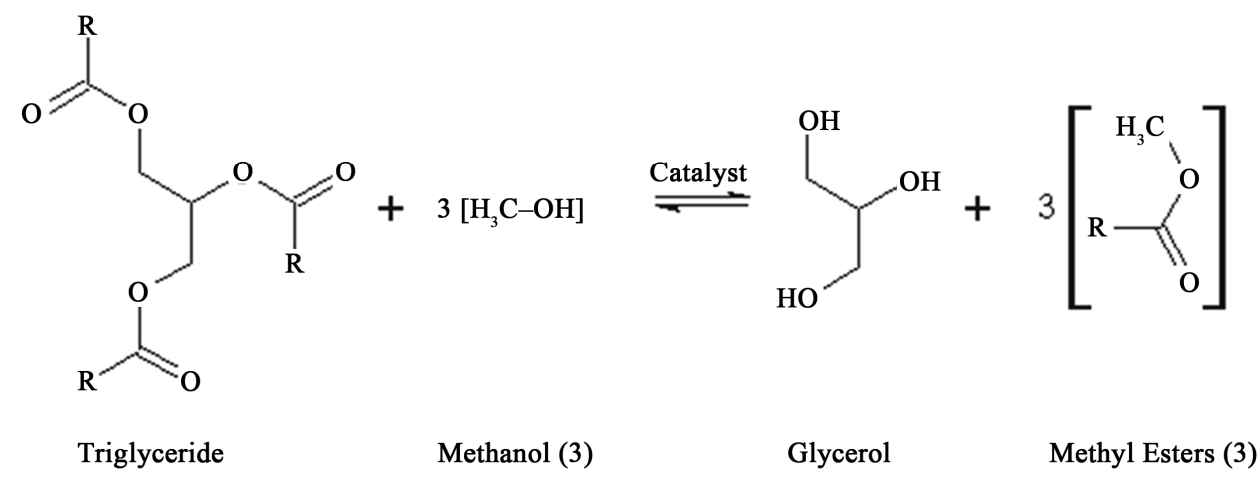

Scheme 1. Transesterification of triglycerides with alcohol. 
synthesize biodiesel like base catalyzed transesterification, acid catalyzed transesterification and enzyme catalyzed transesterification [4]. Biodiesel is currently synthesized using homogeneous acid catalysts, the rate of reaction much slower than the base catalyzed reaction. There are several comprehensive studies of base catalyzed transesterification. The most common basic catalysts are potassium hydroxide $(\mathrm{KOH})$ and sodium hydroxide $(\mathrm{NaOH})[7,8]$. Even though homogeneous catalyzed biodiesel production process are relatively fast and show high conversion with minimal side reactions, they are still not very cost effective with petrodiesel. The transesterification reaction can also be catalyzed by Bronsted acids preferably sulphonic and sulphuric acids, but the reaction rates are very low and require relatively high temperature to get the high product yield [9]. According to an acid catalyzed mechanism for esterification, carboxylic acid can be readily formed by hydrolysis of the carbocation intermediate formed upon protonation of the ester. This suggests that acid catalyzed transesterification should be carried out in the absence of the water to avoid the competetive formation of carboxylic acids and concomitant reduction in the yields of alkyl ester [10]. The most common acid catalysts used are $\mathrm{H}_{2} \mathrm{SO}_{4}$ and $\mathrm{HCl}$. The scientist Freedman et al showed that the methanolysis of soybean oil, in the presence of $1 \mathrm{~mol} \%$ of $\mathrm{H}_{2} \mathrm{SO}_{4}$ with an alcohol/oil molar ratio of $30: 1$ at $65^{\circ} \mathrm{C}$, takes 50 hrs to reach complete conversion of the vegetable oil [11]. The transesterification of oils is also carried out by solid super acids such as tungustated zirconia-alumina (WZA), sulphated tin oxide (STA) and sulphated zirconia-alumina (SZA), of which the WZA catalyst was the most effecttive achieving conversion $>90 \%$ at temperature above $250^{\circ} \mathrm{C}$ after $20 \mathrm{~h}$ [12]. Current industrial catalysts for biodiesel are based on the basic catalyst mentioned above require pretreatment of the feedstock to remove impurities, water and the free fatty acids (which precludes the use of low quality feedstocks such as waste oils) $[13,14]$. They also lead to saponification (i.e. soap formation) of vegetable oil, which occur as an undesired side reaction and necessities lengthy after process separation procedures. These production steps negate the low price of the catalyst and are energy intensive. It is therefore necessary to develop new environmentally benign, inexpensive and effective catalysts which avoid the costly saponification reaction. A wide range of alternatives have been proposed but to date none are ideal. In this work, manganese carbonate $\left(\mathrm{MnCO}_{3}\right)$ was found to be a versatile catalyst in transesterifiction reaction to produce monoalkyl ester (biodiesel). In this communication manganese carbonate was found to be a versatile catalyst with $80 \%$ - 95\% conversion rate in the production of biodiesel involving, vegetable oils like palm oil, rapeseed oil, groundnut oil, coconut oil and castor oil. Although palm oil and rapeseed oil are extensively used for biodiesel production the other oils mentioned are studied for comparison purposes.

\section{Experimental Details}

\subsection{Materials}

All chemicals used in the experiments such as methanol (99.5\%), chloroform, petroleum ether, sodium sulphate, sulphuric acid were of analytical regent grade and silica gel G LR for TLC were purchased from Sarabhai Division Fine Chemicals (Mumbai, India). Refined palm, sunflower, groundnut, coconut, rapeseed and castor oils were purchased from local food store. Pure, ash colored, crystalline manganese carbonate was purchased from Chemical Corporation (Mumbai, India).

\subsection{Transesterification}

Transesterification process was performed in $25 \mathrm{ml}$ round bottom flask with reflux condenser and a magnetic stirrer. Stirring was set at constant speed throughout the experiment. The manganese carbonate in methanol $(0.5 \%-3 \%$ $\mathrm{w} / \mathrm{v}$ ) was used for the conversion of oil to fatty acid methyl ester (FAME), other oil to methanol ratio varied from 5:1 to $12: 1 \mathrm{v} / \mathrm{v}$. A known amount of catalyst was added in the required amount of methanol and was heated separately at desired temperature. This methanolic catalyst was added to the preheated oil and the reaction was kept under reflux condition. Formation of methyl ester from vegetable oil was monitored by thin layer chromatography. After reaction completion, the formed methyl esters mixture was extracted with chloroform dried over sodium sulphate. Chloroform was evaporated using a rotary evaporator and the obtained methyl esters mixture was then subjected to GC-MS analysis.

\subsection{Analysis of Fatty Acid Methyl Esters}

Gas chromatography has been to date the most widely used method for the analysis of biodiesel due to its higher accuracy in unifying minor components [15]. The sample was analyzed with shimadzu GC-2010 gas chromatograph equipped with splitless injection system. Helium was used as carrier gas. The condition of instrument were: column oven temperature $75^{\circ} \mathrm{C}$, injection temperature set at $280^{\circ} \mathrm{C}$, the detection was made with a flame ionization detector (FID) at $310^{\circ} \mathrm{C}$, flow control mode in linear velocity with $26.0 \mathrm{~cm} / \mathrm{sec}$, total flow $14.0 \mathrm{ml} / \mathrm{min}$, column flow $1.0 \mathrm{ml} / \mathrm{min}$, purge flow $3.0 \mathrm{ml} / \mathrm{min}$, pressure 131.6 Kpa where as the split ratio 10.0. Samples were prepared for analysis by adding approximately $0.05 \mathrm{gm}$ of oil phase to $5 \mathrm{ml}$ of n-hexane. About $1 \mathrm{ml}$ of this mixture was put in to GC auto sampler vials. Two micro liters of the sample were injected in to the column. 


\subsection{Recovery of Catalyst}

The catalyst thoroughly washed 4 - 5 times with water for 35 hrs. After complete drying, the catalyst was re-used for transesterification reaction. The obtained results showed a catalytic efficiency of $95 \%$ and decreased after 7 times uses.

\subsection{Fuel Properties of Fatty Acid Methyl Esters}

The product of above transesterification was analyzed, taking into consideration specifications for biodiesel as fuel in diesel engines. The following properties of the biodiesel produced were determined: Density, Acid value, Cloud point, Pour point, Viscosity (By Redwood viscometer), Flash point (By Cleveland's open cup apparatus). Most of these parameters comply with the limits prescribed in the ASTM D6751-02 standards for biodiesel. Each experiment was conducted in triplicate and the data reported as mean.

\section{Results and Discussion}

\subsection{Composition of Oil}

The palm oil was found to give the highest oil yield with $5000 \mathrm{~kg}$ oil per hectare; this value is far higher than other oils which are in the range of hundreds to $2000 \mathrm{~kg}$ oil per hectare. The oil yield from the crops itself is always the key factor to decide the sustainability of feed stock for biodiesel production. Oil crops with higher oil yield are more preferable in the biodiesel industry because it reduces the production cost. The important criteria to determine the sustainability of oil as feedstock for biodiesel is its composition which will subsequently determine the properties of the obtained biodiesel. The composition of the palm, sunflower, groundnut, coconut, rapeseed and castor oils are well reported in literature as shown in

Table 1 The results showed that the Palm oil contains the $85 \%$ saturated acids (palmitic and stearic) and 15\% unsaturated acids (linoleic, oleic). Rapeseed oil contains
86.4\% unsaturated acids and only 4.4\% saturated acid. Sunflower and castor oil showed high content of linoleic $73 \%$ and ricinoleic acid $89 \%$ respectively. The different results obtained in the properties of biodiesel is due to the variation of compositions of oils. The palm oil has $40 \%$ oleic and $45 \%$ palmitic acid as major components and the composition of sunflower, coconut, rapeseed, castor oils differ in the fatty acid compositions. The rapeseed oil has $64 \%$ of oleic acid as major component. This could be the reason why this is preferred oil for the production of biodiesel in Europe. In contrast castor oil has 89.5\% of recinoleic acid as major component which forms resins as effects transesterification and so is not a preferred oil for the producing biodiesel. By and large the oils studied exhibit $85 \%$ and above composition of saturated acids and facilitate the production of biodiesel in large quantity. The oil composition of palm, sunflower, groundnut, coconut, rapeseed and castor oils is shown in Table 1.

\subsection{Analytical Results}

In order to study the obtained biodiesels composition, GC-MS analysis was used for the determination of the composition of the obtained fatty acid methyl esters. The retention times in minute for palm, sunflower, coconut and rapeseed oils are 10.763 - 26.885, 10.893 - 27.300, 14.739 - 26.380 and 10.763 - 26.885 respectively. The percentage for palm, sunflower, coconut and rapeseed oils are $100.01 \%$, 99.99\%, $100 \%$, and $100.01 \%$ respecttively. The obtained qualitative and quantitative analysis and the result of methyl ester components in palm and sunflower transesterification products are presented in Table 2.

The Table 2 indicates that the FAME from sunflower oil contained mainly methyl linoleate (47.43\%) and methyl oleate (32.49\%), which are comparable to fatty acid composition of same feedstock. While palm oil methyl esters consisted mainly of methyl palmitate (42.42\%) and oleate $(47.04 \%)$.

Table 1. Composition of various oils in \%.

\begin{tabular}{|c|c|c|c|c|c|c|}
\hline $\begin{array}{l}\text { Fatty acid } \\
\text { composition (\%) }\end{array}$ & Molecular formula & Palm & Sunflower & Coconut & Rapeseed & Castor \\
\hline Oleic & $\mathrm{C}_{18} \mathrm{H}_{34} \mathrm{O}_{2}$ & 40.0 & 16.93 & 0.3 & 64.1 & 3.0 \\
\hline Linoleic & $\mathrm{C}_{18} \mathrm{H}_{32} \mathrm{O}_{2}$ & 10.0 & 73.73 & 0.2 & 22.3 & 4.2 \\
\hline Palmitic & $\mathrm{C}_{16} \mathrm{H}_{32} \mathrm{O}_{2}$ & 45.0 & 6.8 & 0.2 & 3.5 & 1.0 \\
\hline Stearic & $\mathrm{C}_{18} \mathrm{H}_{36} \mathrm{O}_{2}$ & 5.0 & 3.26 & 0.2 & 0.9 & 1.0 \\
\hline Linolenic & $\mathrm{C}_{18} \mathrm{H}_{30} \mathrm{O}_{2}$ & - & 00 & - & - & 0.3 \\
\hline Eicosenoic & $\mathrm{C}_{20} \mathrm{H}_{38} \mathrm{O}_{2}$ & - & - & - & - & 0.3 \\
\hline Ricinoleic & $\mathrm{C}_{18} \mathrm{H}_{34} \mathrm{O}_{3}$ & - & - & - & - & 89.5 \\
\hline Dihydroxysteric & $\mathrm{C}_{18} \mathrm{H}_{36} \mathrm{O}_{4}$ & - & - & - & - & 0.7 \\
\hline Palmitoleic & $\mathrm{C}_{16} \mathrm{H}_{30} \mathrm{O}_{2}$ & - & - & - & 0.1 & - \\
\hline Myristic & & & & 0.3 & & \\
\hline Others & - & - & - & - & 9.1 & - \\
\hline
\end{tabular}


Table 2. The analytical results of components of FAME from various vegetable oils using $\mathrm{MnCO}_{3}$ catalyst.

\begin{tabular}{lcccc}
\hline Methyl ester & Palmoil \% & Sunflower \% & Coconutoil \% & Rapeseed oil \% \\
\hline Methyl laurate & 0.41 & 0.06 & 54.39 & 0.41 \\
Methyl myristate & 1.24 & 0.10 & 21.40 & 1.24 \\
Methyl palmitate & 42.42 & 14.96 & 10.58 & 42.42 \\
Methyl palmitoleate & 0.28 & 1.10 & 0.24 & 0.28 \\
Methyl stearate & 3.30 & 3.85 & 1.69 & 3.30 \\
Methyl oleate & 47.04 & 32.49 & 6.41 & 47.04 \\
Methyl linoleate & 5.32 & 47.43 & 5.29 & 5.32 \\
\hline
\end{tabular}

\subsection{Fuel Properties of Methyl Esters}

The fuel properties of the obtained biodiesel are summarized in Table 3 together with the relevant specifications in the ASTM biodiesel standards [16-19]. The properties of methyl esters obtained from different oils were compared with ASTM biodiesel standards. The results are shown in Table 3. Viscosity of the methyl esters obtained from the different studied oils was within the standard range of $3.5-5.0 \mathrm{~mm}^{2} / \mathrm{s}$ at $40^{\circ} \mathrm{C}$. Hence no negative impact on fuel injector's system performance means produced biodiesel can be use in existing diesel engine. Flash point measures the tendency of the sample to form flammable mixture with air under controlled laboratory conditions. This is the only property that must be considered on assessing the inflammability hazard of the material. The flash point of methyl esters of studied oils is above the specification limits and is safe for transport.

In comparison with other solid catalysts such as $\mathrm{KF} /$ $\mathrm{MgAl}$ hydrotalcite, CaO-supported catalysts ( $\mathrm{Li} / \mathrm{Cao}, \mathrm{Na} / \mathrm{CaO}$, $\mathrm{K} / \mathrm{Cao}$ ) was the effective achieving conversion more than 85\% [12,16,20-23]. Manganese carbonate was found to be a green versatile catalyst which gives high biodiesel yield at low temperatures. Use of manganese carbonate may lead to cheaper production cost by enabling reuse of the catalyst and opportunities to operate in fixed bed continuous process. The process offers advantages in terms of mild conditions, high conversion and practical viability and may find commercial application for the biodiesel production.

\subsection{Effect of Methanol to Oil Ratio}

The amount of alcohol added to vegetable oil is one of the important factors that affect conversion efficiency as well as production cost of biodiesel. The conversion efficiency is defined as the yield of the process represented in terms of percentage. Generally the amount of alcohol required for transesterification reaction is analyzed in terms of volumetric ratio. Stoichiometriclly, the alcohol/ oil molar ratio is 3:1. Higher amount of alcohol is required to drive the reaction to completion at faster rate. It is observed that lower amount of alcohol requires longer reaction periods. The conversion efficiency of transeste- rification reaction with increasing amount of alcohol obtained during present study is shown in Figure 1. The transesterifiction reaction was studied for different molar ratios. The methanol to oil molar ratio varied from oil to oil. The maximum ester conversion for palm oil was found to be $90 \%$ - 95\% with a methanol to oil ratio of 5:1. In the case of sunflower and rapeseed oil maximum yield of $90 \%$ was obtained at 7:1 methanol oil ratio. The groundnut oil requires 9:1 ratio for the maximum conversion, while in case of coconut and castor yield achieved was $75 \%$ at $12: 1$ methanol to oil ratio which gives highest conversion of oil to methyl ester. Figure 1 depicts the effect of alcohol to oil molar ratio on the conversion of oil to methyl ester.

\subsection{Effect of Catalyst Amount}

The catalyst amount in the range $0.5 \%-3.0 \%$ (Weight of catalyst/volume of oil) is used in the present experimenttal analysis. The effect of catalyst amount on conversion efficiency is shown in Figure 2. The obtained results showed that the yield of palm and rapeseed oil was 95\% and $90 \%$ obtained with a $1 \%$ of catalyst amount while sunflower and groundnut oil gave better yields, 90\% and $85 \%$ respectively with $1.5 \%$ catalyst amount. Finally, the yield of $75 \%$ was obtained in the case of castor and coconut oils with $1.5 \%$ and $2.0 \%$ catalyst amount - respectively.

\subsection{Effect of Reaction Temperature}

Although the reflux temperature was in general $600^{\circ} \mathrm{C}$ $80^{\circ} \mathrm{C}$, the reactions temperature and the obtained results are shown in Figure 3 and showed that the temperature required for the complete conversion of oil to fatty acid methyl esters varied from oil to oil. In the case of palm and sunflower oils, highest yield of 95\% and 90\% were obtained at $60^{\circ} \mathrm{C}$ respectively, while for groundnut, coconut, rapeseed and castor oils, the optimum yields obtained were $85 \%, 75 \%, 90 \%$ and $75 \%$ respectively and were obtained at $70^{\circ} \mathrm{C}$. It was observed that for reaction temperature below $60^{\circ} \mathrm{C}$, saponification of glycerides occurs very fast. 
Table 3. Fuel properties of produced fatty acid methyl esters.

\begin{tabular}{|c|c|c|c|c|c|c|}
\hline Properties & Palm oil & Sunflower & Coconut & Rapeseed & Castor & $\begin{array}{l}\text { ASTM biodiesel } \\
\text { standard }\end{array}$ \\
\hline Viscosity $\mathrm{mm}^{2} / \mathrm{s}$ at $40^{\circ} \mathrm{C}$ & 4.42 & 3.26 & 3.9 & 3.51 & 5.0 & $3.5-5.0$ \\
\hline flash point $\left({ }^{\circ} \mathrm{C}\right)$ & 162 & 180 & 171 & 150 & 190 & $130 \mathrm{~min}$ \\
\hline Cloud point $\left({ }^{\circ} \mathrm{C}\right)$ & 5 & 4 & 6 & -4 & -3 & $-3-12$ \\
\hline Pour point $\left({ }^{\circ} \mathrm{C}\right)$ & 10 & 9 & 9 & -12 & -8 & $-15-10$ \\
\hline Density $\mathrm{Kg} / \mathrm{m}^{3}$ & 0.92 & 0.92 & 0.91 & 0.91 & 0.96 & $0.87-0.90$ \\
\hline Acid value mg KOH/g & 0.1 & 0.15 & 0.3 & 0.89 & 2.0 & 0.5 \\
\hline
\end{tabular}

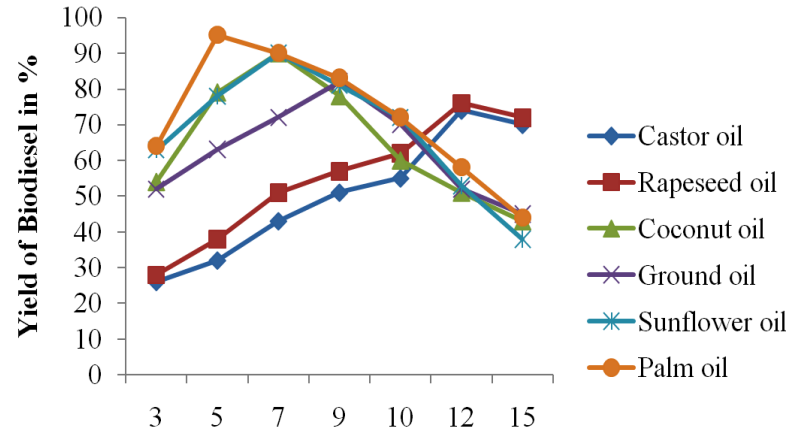

Methanol/oil molar ratio

Figure 1. Effect of methanol/oil molar ratio.

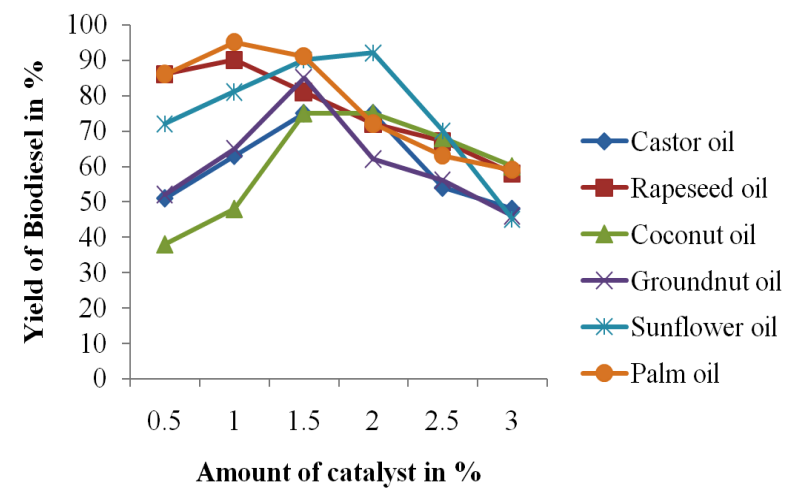

Figure 2. Effect of amount of catalyst.

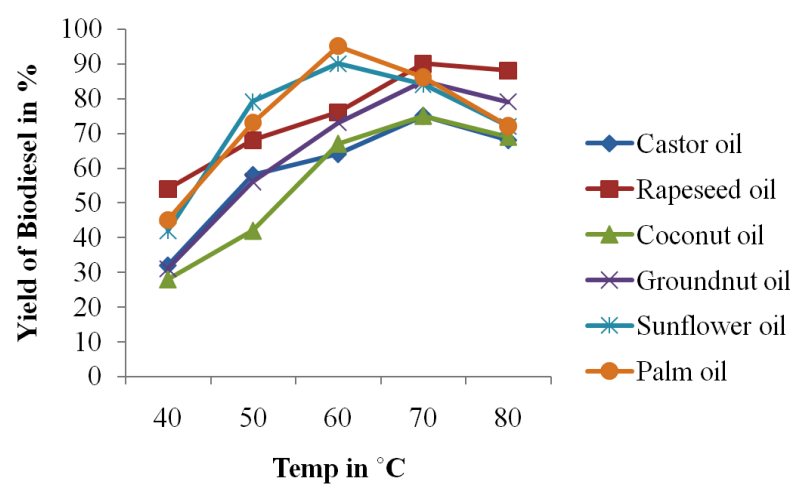

Figure 3. Effect of reaction temperature.

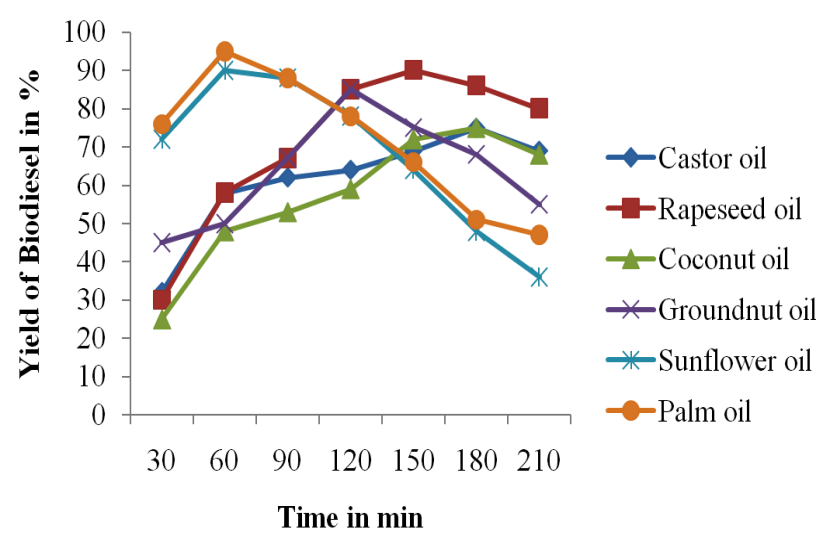

Figure 4. Effect of reaction time.

\subsection{Effect of Reaction Time}

In order to study the effect of reaction of reaction time, experiments were carried out between 30 to $210 \mathrm{~min}$ for the studied oils and the obtained results are depicted in Figure 4. The obtained results showed that palm and sunflower oils achieved highest yield of $95 \%$ and $90 \%$ respectively at 60 min under reflux conditions. Groundnut and rapeseed oil gives $85 \%$ and $90 \%$ yield at 120 and 150 min respectively; while the transesterifiction yield of $75 \%$ was obtained in case of coconut and castor oils maximum time of 180 minutes was sufficient for the completion of reaction with highest yield of biodiesel.

\subsection{Recovery and Reuse of Catalyst}

Recovery of catalyst from the reaction mixture is an important operational parameter. From a financial economic point of view, the use of heterogeneous catalyst in biodiesel production could reduce its price becoming competitive with diesel. The used catalyst was recovered and reused for further transesterification reactions. The obtained results showed the recovered catalyst was still efficient even after seven successive uses. This suggests that the use of manganese carbonate could be a fruitful approach for biodiesel production. 


\section{Conclusion}

In this paper, we have evaluated the catalytic activity of crystalline $\mathrm{MnCO}_{3}$ as green catalyst since $\mathrm{MnCO}_{3}$ is non corrosive, easy to handle and environmentally friendly and an alternative low cost catalyst. $\mathrm{MnCO}_{3}$ efficiently promote the transesterification in methanol solutions and in the presence of vegetable oils. The high yields achievable under mild reaction conditions are comparable to those obtained with a common acid catalyst such as acid and base. Therefore it is demonstrated that, $\mathrm{MnCO}_{3}$ is a potential catalyst for the production of biodiesel which is a low-cost raw materials. The advantage of this protocol is the use of an available low-cost catalyst, which is easy to manipulate and potentially less corrosive. The results of this work suggest $\mathrm{MnCO}_{3}$ as a promising alternative catalyst for the production of biodiesel. As a final remark, we believe that the application of $\mathrm{MnCO}_{3}$ potentially promote a reduction of the costs related to biodiesel production.

\section{Acknowledgements}

The financial support provided by University Grants Commission, New Delhi, F.No.34-316/2008 (SR) is gratefully acknowledged. The authors also thank the Principal, Dr. C.S.N.Sharma, Govt. City College, Hyderabad-500002 for kind cooperation and encouragement.

\section{REFERENCES}

[1] G. Antoline, F. Tinaut, Y. Briceno, V. Castano, C. Perez and A. Ramirez, "Optimition of Biodiesel Production by Sunflower Oil Trnsesterifiction,” Bioresource Technology, Vol. 83, No. 2, 2002, pp. 111-114. doi:10.1016/S0960-8524(01)00200-0

[2] G. Vicente, M. Mrtine and J. Arcil, "Integrted Biodiesel Production: A Comparison of Different Homogeneous Systems," Bioresource Technology, Vol. 92, No. 3, 2004, pp. 297-305. doi:10.1016/j.biortech.2003.08.014

[3] U. Schuchardt, R. Serchelia and R. M. Vargas, “Transesterification of Vegetble Oils: A Review,” Journal of Brazilian Chemical Society, Vol. 9, No. 3, 1997, pp. 199-210.

[4] Y. C. Dennis, X. Wu and M. K. H. Leung, "A Review on Biodiesel Production Using Catalyzed Transesterifiction,” Applied Energy, Vol. 87, No. 4, 2010, pp. 1083-1095. doi:10.1016/j.apenergy.2009.10.006

[5] L. F. Razon, "Alternative Crops for Biodiesel Feedstock," $C A B$ Reviews: Perspectives in Agriculture, Veterinary Science, Nutrition and Natural Resources, Vol. 4, No. 56, 2009, pp. 1-15. doi:10.1079/PAVSNNR20094056

[6] M. Canakci, "The Potential of Restaurant Waste Lipids Biodiesel Feedstock,” Bioresource Technology, Vol. 98, No. 1, 2007, pp. 183-190. doi:10.1016/j.biortech.2005.11.022

[7] B. Freedman, E. H. Pryde and W. F. Kwolek, "Thin Layer Chromatography/FID Analysis of Transesterified Vege- table Oils,” Journal of American Oil Chemists' Society, Vol. 61, No. 7, 1984, pp. 1638-1643.

doi:10.1007/BF02541649

[8] D. Darnoko and M. Cheryan, "Kinetics of Palm Oil Transesterification in a Batch Reactor," Journal of American Oil Chemists' Society, Vol. 77, No. 12, 2000, pp. 12631267. doi:10.1007/s11746-000-0198-y

[9] K. J. Harrington and C. D. Arcy-Evans, "Transesterification in Situ of Sunflower Oil,” Industrial and Engineering Chemistry Product Research and Development, Vol. 24, No. 2, 1985, 314-318. doi:10.1021/i300018a027

[10] W. Stoffel, F. Chu and E. H. Ahrens, "Analysis of Long Chain Fatty Acids by Acids by Gas-Iquid Chromatography," Journal of Analytical Chemistry, Vol. 31, No. 2, 1959, pp. 307-308. doi:10.1021/ac60146a047

[11] B. Freedman, R. O. Butterfield and E. H. Pryde, “Transesterification Kinetics of Soybean Oil," Journal of American Oil Chemists' Society, Vol. 63, No. 10, 1986, pp. 1375-1380. doi:10.1007/BF02679606

[12] S. Furuta, H. Matsuhshi and K. Arata, "Biodiesel Fuel Production with Solid Superacid Catalysis in Fixed Bed Reactor under Atmospheric Pressure," Catalysis Communication, Vol. 5, No. 12, 2004, pp. 721-723. doi:10.1016/j.catcom.2004.09.001

[13] K. Narsimharao, A. Lee and K. J. Wilson, "Catalyst in Production of Biodiesel: A Review,” Biobased Materials and Bioenergy, Vol. 1, No. 1, 2007, pp. 19-30.

[14] M. M. Gui, K. T. Lee and S. Bhatia, "Flexibility of Edible Oil vs. Non-Edible Oil vs. Waste Oil as Biodiesel Feedstock,” Energy, Vol. 33, No. 11, 2008, pp. 1646-1653. doi:10.1016/j.energy.2008.06.002

[15] R. C. Schneider, V. Z. Baldissrelli, F. Trombetta, M. Martinelli and E. B. Caramao, "Optimization of Gas Chromatographic-Mass Spectrometric Analysis for Fatty Acids in Hydrogenated Castor Oil Obtained by Catalytic Transfer Hydrogenation,” Analytica Chimica Acta, Vol. 505, No. 2, 2004, pp. 223-226. doi:10.1029/2004JD005394

[16] H. Fukuda, A. Kondo and H. J. Noda, "Biodiesel Fuel Production by Transesterification of Oil," Bioscience Bioenergy, Vol. 92, No. 5, 2001, pp. 405-416. doi:10.1263/jbb.92.405

[17] P. Bondioli, "The Properties of Fatty Acid Esters by Means of Catalytic Reactions,” Topics in Catalysis, Vol. 27, No. 1-4, 2004, pp. 77-81. doi:10.1023/B:TOCA.0000013542.58801.49

[18] A. Murugesan, C. Umarani, T. R. Chinnusamy, M. Krishnan, R. Subramanian and N. Neduzchezhain, "Production and Analysis of Biodiesel from Non-Edible Oils-A Review," Renewable and Sustainable Energy Reviews, Vol. 13, No. 4, 2009, pp. 825-834. doi:10.1016/j.rser.2008.02.003

[19] S. P. Singh and D. Singh, "Biodiesel Production through the Use of Different Sources and Characterization of Oils and Their Esters as the Substitute of Diesels: A Review," Renewable and Sustainable Energy Reviews, Vol. 14, No. 1, 2010, pp. 200-216. doi:10.1016/j.rser.2009.07.017

[20] K. F. Peter, R. Ganswindt, H. P. Neuner and E. Weidner, "Alcoholysis of Triglycerols by Heterogeneous Cataly- 
sis,” European Journal of Lipid Science Technology, Vol. 104, No. 6, 2002 pp. 324-330. doi:10.1002/1438-9312(200206)104:6<324::AID-EJLT32 4>3.0.CO;2-D

[21] G. J. Suppes, S. Bockwinkel, S. Lucas, J. B. Botts, M. H. Mason and A. J. Heppert, "Calcium Carbonate Catalyzed Alcoholysis of Fats and Oils," Journal of American Oil Chemical Society, Vol. 78, No. 2, 2001, pp. 139-145. doi:10.1007/s11746-001-0234-y
[22] E. Leclereq, A. Finiels and C. Moreau, “Transesterification of Rapeseed Oil in the Presence of Basic Zeolites and Related Solid Catalyst,” Journal of American Oil Chemist's Society, Vol. 78, No. 11, 2001, pp. 1161-1165. doi:10.1007/s11746-001-0406-9

[23] D. W. Lee, Y. M. Park and K. Y. Lee, "Heterogeneous Base Catalysts for Transesterification in Biodiesel Synthesis," Catalysis Surveys from Asia, Vol. 13, No. 2, 2009, pp. 63-77. 